\title{
Modeling of Positive Switching Impulse Discharge of UHV Transmission Line Air Gaps
}

\author{
Jiachen Gao, Linong Wang *, Qiushi Zhang and Bin Song \\ School of Electrical Engineering and Automation, Wuhan University, Wuhan 430000, China; \\ whugaojc@whu.edu.cn (J.G.); qiushizhang@126.com (Q.Z.); songbin72@163.com (B.S.) \\ * Correspondence: wangln@whu.edu.cn; Tel.: +86-138-7120-8599
}

Received: 19 November 2018; Accepted: 10 December 2018; Published: 12 December 2018

\begin{abstract}
Positive switching impulse discharge characteristics are an important basis for the external insulation design of transmission line towers. At present, the characteristics are obtained mainly by real tower discharge tests. Since the existing research on the discharge model is not perfect, test designs are not reasonable, which results in high costs. The influence of line height and tower width on the discharge characteristics of Ultra High Voltage (UHV) transmission lines air gaps is studied in this paper. The results show that the line height had little influence on the breakdown voltage of air gaps in UHV transmission lines. A tower-width discharge model was obtained by fitting the breakdown voltage of air gaps with different gap lengths and tower widths. By analyzing the gap characteristic factors of different transmission lines, a discharge model of different tower air gaps in UHV transmission lines was presented. The breakdown voltage calculated by the models was in good agreement with the test results, and the errors were not more than $5 \%$.
\end{abstract}

Keywords: UHV transmission lines; discharge model; long air gaps; switching impulse

\section{Introduction}

In order to solve the problem of reverse distribution of energy resources and load centers, China has carried out a great deal of research and construction work on Ultra High Voltage (UHV) transmission lines since the beginning of the 21st century. UHV transmission lines stand for alternating current (AC) transmission lines with voltage levels of $1000 \mathrm{kV}$ and above, and direct current (DC) transmissions with voltage levels of $\pm 800 \mathrm{kV}$ and above, which have the characteristics of large transmission capacity, long transmission distance, and low line loss. At present, China has put into operation several $1000 \mathrm{kV}$ AC and $\pm 800 \mathrm{kV}$ DC UHV transmission lines [1].

In transmission lines, the air gap is the main external insulation mode of towers. In the design process of transmission lines, the choice of air gaps is very important. Reasonable design is not only related to the safe and stable operation of the system, but also to the cost of the project. Compared with power frequency and lightning overvoltage, the air gap required to withstand switching impulse overvoltage is the largest. Moreover, according to past test results, the positive switching impulse breakdown voltage of the same gap is significantly lower than the negative switching impulse breakdown voltage [2]. Therefore, the positive switching impulse discharge characteristics are an important basis for the external insulation design of transmission line towers.

The air gaps in transmission lines belong to long air gaps. The discharge characteristics of long air gaps are complex and have been the focus of research in high voltage transmission projects for many years. In past decades, scholars have carried out a lot of research on long air gap discharge characteristics. In the 1960s, some scholars studied the discharge characteristics under switching impulse, obtained the breakdown characteristics of different gap structures through a large number of tests, and established several empirical formulas for calculating the discharge voltage [3-5]. Since the 
1970s, some scholars have carried out tests on the discharge characteristics of power transmission and transformation projects to provide a basis for Extra High Voltage (EHV) and UHV transmission projects [6-8]. In the 1980s, some scholars established a typical gap breakdown voltage calculation model based on the leader discharge mechanism $[9,10]$. Since the 21st century, with the continuous progress of technology, scholars have carried out long air gap breakdown voltage prediction calculation and observation tests [11-19], further promoting the research process of long air gap discharge. At present, scholars mainly adopt real tower discharge tests to obtain the positive switching impulse discharge characteristics of air gaps in UHV transmission lines. Since the research on the discharge model is not perfect, test designs are not reasonable and therefore have high costs. In order to solve this problem, this paper studies the discharge characteristics of air gaps in UHV transmission lines, and obtains the discharge models.

\section{Breakdown Voltage Calculation Method}

\subsection{Long Air Gap Discharge Model}

The development process of air gap discharge in UHV transmission lines is mainly composed of some physical processes, such as the first corona initiation, the streamer-leader transformation, the continuous leader development, and the final jump under positive switching impulse [20,21]. The voltage rise of the conductor causes the surface electric field distortion and the first corona initiates. After obtaining the free charge from the air, the first corona is transformed into the streamer and develops in the gap. In long air gaps, the streamer is unable to complete the breakdown of the whole gap. As the conductor voltage increases further, the streamer stem is transformed into a leader and continues to extend. When the streamer ahead of the leader reaches the ground potential electrode, the discharge goes into the final jump, as shown in Figure 1.

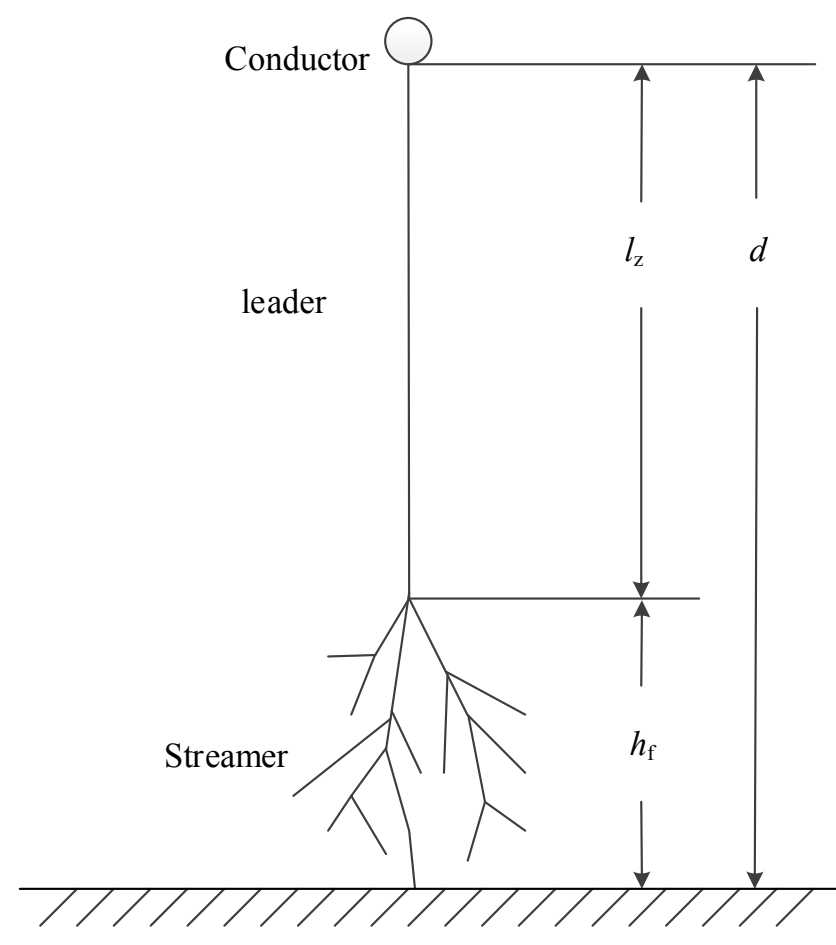

Figure 1. The development process of air gap discharge.

In the course of the discharge development, gap breakdown must meet two basic conditions: the continuous leader inception, and the streamer in front of the leader developing to the ground potential electrode. When the free charges generated by the streamer are sufficient to maintain the continuous development of the leader, the applied voltage of the conductor is the continuous leader inception 
voltage. After the inception of the continuous leader, the leader develops at an almost constant speed in the gap, and the potential of the leader head nearly remains the continuous leader inception voltage. When the streamer in front of the leader reaches the ground potential tower, the leader develops rapidly and gap breakdown becomes inevitable. At this time, the applied voltage of the conductor is the minimum breakdown voltage. It can be concluded that the minimum breakdown voltage of long air gaps consists of two parts [10]:

$$
U_{B}=U_{l c}+\Delta U_{l}
$$

where $U_{B}$ is the minimum breakdown voltage, $U_{l c}$ is the continuous leader inception voltage, and $\Delta U_{l}$ is the leader voltage drop.

The leader can be regarded as a channel with arc characteristics, and the expression of the leader voltage drop can be obtained:

$$
\Delta U_{l}=50 l_{z}+37.5 \ln \left[8-7 e^{-1.33 l_{z}}\right]
$$

where $l_{z}$ is the length of the leader.

When the streamer in front of the leader reaches the ground potential electrode, the length of the leader channel is:

$$
l_{z}=d-h_{f}
$$

where $d$ is the gap length, and $h_{f}$ is the length of the final jump.

According to the characteristic that the potential gradient $E_{S}$ of the streamer is almost constant, the relationship between the continuous leader inception voltage $U_{l c}$ and the final jump length $h_{f}$ can be obtained:

$$
h_{f}=\frac{U_{l c}}{E_{s}}
$$

The expression of the minimum breakdown voltage of long air gaps can be obtained from the above equations:

$$
U_{B}=U_{l c}+50\left(d-\frac{U_{l c}}{E_{s}}\right)+37.5 \ln \left[8-7 e^{-1.33\left(d-\frac{U_{l c}}{E_{s}}\right)}\right]
$$

According to the dispersibility of the discharge process and the randomness of the breakdown path, the $50 \%$ breakdown voltage $U_{50}$ of the air gaps under the critical positive switching impulse is related to the minimum breakdown voltage $U_{B}$ [9]:

$$
U_{50}=\frac{U_{B}}{1-3 \sigma}
$$

where $\sigma$ is the standard deviation of the probability function of the breakdown, which is $3 \%$ in conductor-tower gaps.

It can be seen that the continuous leader inception voltage is the key to calculating the long air gap breakdown voltage.

According to the two basic conditions, F.A.M. Rizk set a point charge at a distance $s$ from the tip of the streamer stem equivalent to the space charge that is generated by the streamer discharge [10]:

$$
U_{l c}=U_{c}+\alpha U_{i n}
$$

where $\alpha$ is the ratio function between the equivalent radius of the streamer stem region and the distance $s$ from the point charge $Q_{0}$ to the tip of the streamer stem, $U_{c}$ is the critical voltage, and $U_{i n}$ is the induction voltage generated by the equivalent charge $Q_{0}$ and its induction charge at the tip of the streamer stem, which can be expressed as:

$$
U_{i n}=U_{i a}-U_{i b}
$$


where $U_{i a}$ is the induced potential at the tip of the streamer stem due to the equivalent charge $Q_{0}$. $U_{i b}$ represents the absolute value of the potential at the tip of the streamer stem induced by image charges induced on the grounding electrode and other nearby objects [10]. As the length of the stem is very small, it can be considered:

$$
\begin{aligned}
U_{i a} & =\frac{Q_{0}}{4 \pi \varepsilon_{0} S} \\
U_{i b} & =\frac{Q_{0}}{4 \pi \varepsilon_{0} R}
\end{aligned}
$$

where $R$ is the gap characteristic factor which characterizes the gap geometry, gap spacing, nature and dimensions of the grounding electrode, etc.

Thus, a general model of the continuous leader inception voltage of any gap is obtained [10]:

$$
U_{l c}=\frac{U_{c \infty}}{1+\frac{A}{R}}
$$

where $U_{c \infty}$ and $A$ are related to the structure of a high voltage electrode, but not to the gap length and the structure of a grounding electrode.

In the gap of the conductor electrode with a gap length of 4-8 $\mathrm{m}$, the general model of the continuous leader inception voltage is [15]:

$$
U_{l c}=\frac{U_{c \infty}}{1+\frac{A}{R}}=\frac{2247}{1+\frac{9.87-10.53 \ln a}{(2.64-\ln a) R}}
$$

where $a$ is the radius of the conductor.

The continuous leader inception voltage model of conductor-plane gaps is [10]:

$$
U_{l c}=\frac{U_{c \infty}}{1+\frac{A}{R}}=\frac{2247}{1+\frac{5.15-5.49 \ln a}{d \ln \frac{2 d}{a}}}
$$

\subsection{Method}

According to the above discharge voltage calculation model, the disparity in the continuous leader inception voltage results in the difference in breakdown voltage in various air gaps of transmission lines. The difference in the continuous leader inception voltage is caused by the difference in gap structure. Therefore, the calculation of the gap characteristic factor, which represents the structural difference, becomes the key to calculating the breakdown voltage of air gaps. In fact, the gap characteristic factor represents the ability of the induced charge on the surrounding grounding structure to generate the induced potential on the surface of the high voltage electrode. F.A.M. Rizk calculated the gap characteristic factors of some typical gaps by a mathematical method $[9,10]$. A gap characteristic factor calculation method is proposed in [15]. This method sets an equivalent point charge in a finite element simulation software to determine the induced potential on the surface of the high voltage electrode so as to calculate the factor. It is difficult to calculate the gap characteristic factor of complex gaps by the mathematical method, whereas the finite element simulation method can calculate the gap characteristic factor of any gap. In order to calculate the breakdown voltage of different gaps, the finite element simulation method was adopted in this paper.

The flow chart of the finite element simulation method is shown in Figure 2. First, a solid model of the gap was made in Solidworks. The model was then imported into Comsol Multiphyscis. Subsequently, the shortest distance between the conductor and the tower was determined to be the breakdown path, and the gap length was the discharge path length $d$. Thereafter, on the breakdown path, a point charge $Q_{0}$ was set at a distance of $s$ to the surface of the conductor. In this study, the initial leader length was about $0.7 \mathrm{~m}[22,23]$, and the value of $s$ was in the range of $0.3-0.7 \mathrm{~m}$ and thus had little influence on the gap characteristic factor [15]. Therefore, the charge was considered away from 
the surface of the conductor $0.5 \mathrm{~m}$ in this paper. According to equations (8), (9), and (10), it can be considered that the value of the $Q_{0}$ has no effect on the gap characteristic factor [15], so the value of $Q_{0}$ was considered as $1 \mathrm{C}$ in this paper. That is to say, on the breakdown path, a point charge of $1 \mathrm{C}$ was set at the position of $0.5 \mathrm{~m}$ from the surface of the conductor. Then, the boundary conditions were set so that the potential at infinity was zero, consequently grounding the tower. The induced voltage calculated by this method was actually the induced voltage at the tip of the streamer stem. Because the length of the streamer stem was very small, it was considered that the tip of the streamer stem was on the surface of the conductor. Therefore, although the conductor was an equipotential body, the method actually calculated the potential of a small distance outside of the conductor, indicating that the relevant boundary conditions were not set. After the boundary conditions were set, the potential $U_{i n}$ of the point on the surface of the conductor was obtained by analysis and calculation. The gap characteristic factor and the breakdown voltage of the gap were calculated by the long air gap discharge model.

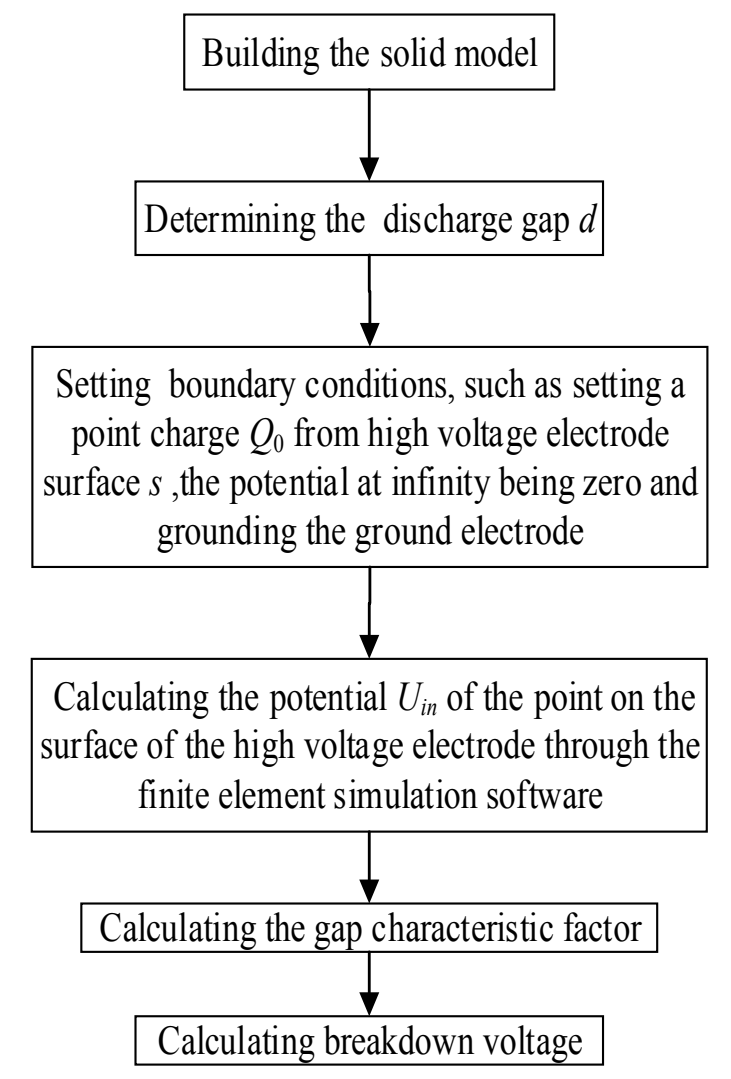

Figure 2. Flow chart of the finite element simulation method.

\section{Discharge Characteristics}

\subsection{Equivalent of Bundle-Conductor}

In UHV transmission lines, most conductors are bundle-conductors. In order to simplify the research process, the bundle-conductor can be equivalent to a single conductor. According to the principle of capacitance equivalence, a bundle-conductor can be equivalent to a single conductor along the axis, and the expression of the radius of the equivalent conductor is as follows [24]:

$$
a_{e}=\left(n a_{l} r_{b}^{n-1}\right)^{\frac{1}{n}}
$$

where $a_{e}$ is the radius of the equivalent conductor, $a_{l}$ is the radius of the single conductor of the bundle-conductor, $r_{b}$ is the bundle radius, and $n$ is the number of conductors in the bundle-conductor. 
According to the charge simulation method, F.A.M Rizk presented the continuous leader inception model of bundle-conductor-plane gaps [10,24]:

$$
U_{l c}=\frac{2247}{1+\frac{5.15-5.49 \ln a}{d \ln \frac{2 d}{a}}}=\frac{2247}{1+\frac{5.15-5.49 \ln a_{e}}{d \ln \frac{2 d+r_{b}+a_{l}}{a_{e}}}}
$$

The single conductor was used instead of the bundle-conductor in the following research.

\subsection{Influence of Line Height}

Previous testing studies have shown that in transmission lines, with the increase of line height, the influence of height on the air gap breakdown voltage is reduced [2]. UHV transmission line towers are enormous in height, thus it is difficult to judge the influence of line height on breakdown voltage. In order to investigate the influence of line height in UHV transmission lines, the breakdown voltage of air gaps with different heights was studied using the breakdown voltage calculation method. Since the line height in UHV transmission lines is generally above $25 \mathrm{~m}$, the conductor-tower gaps with line heights of $25 \mathrm{~m}, 30 \mathrm{~m}, 35 \mathrm{~m}$, and $40 \mathrm{~m}$ were selected to study in this paper.

The gap diagrammatic sketch and solid model are shown in Figure 3. The radius of the conductor was $0.05 \mathrm{~m}$ and the length was $20 \mathrm{~m}$. The gap length $\mathrm{d}$ was the distance from the surface of conductor to the tower leg, which was $5 \mathrm{~m}$. The line height $\mathrm{h}$ was the distance from the surface of the conductor to the ground. The breakdown voltage of four different line height gaps was calculated by the breakdown voltage calculation method. The results are shown in Figure 4 . The results show that the variety of breakdown voltage was not more than $1 \%$. Slight changes were possibly due to the insufficient height of the tower. However, it was concluded that the line height had little effect on the breakdown voltage of air gaps in UHV transmission lines.

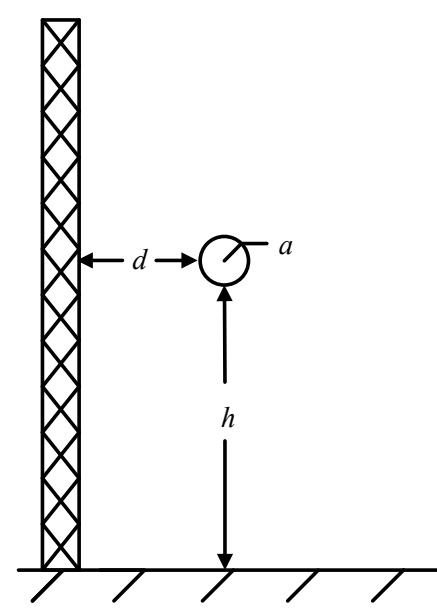

(a) Diagrammatic sketch

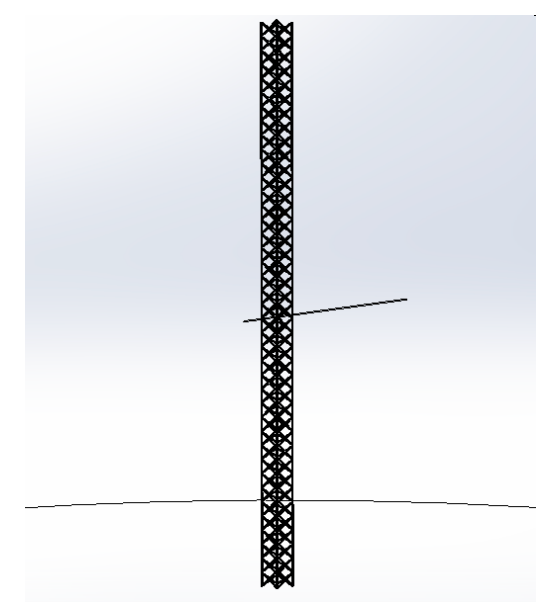

(b) Solid model

Figure 3. Research on line height.

\subsection{The Influence of Tower Width}

According to [25], the relationship between the breakdown voltage and the width of the tower is the following:

$$
U_{50(w)}=U_{50(1)}(1.03-0.03 w)
$$

where $U_{50(w)}$ is the breakdown voltage with the tower width of $w$, and $U_{50(1)}$ is the breakdown voltage with the tower width of $1 \mathrm{~m}$.

However, in previous tests and studies, there was a certain discrepancy between the results and the equation. According to [15], as the width of the tower increases, the breakdown voltage decreases. 
As the gap length increases, the influence of the tower width on breakdown voltage will decrease. Therefore, the influence of gap length cannot be ignored. In order to determine the influence of tower widths and gap lengths on the breakdown of UHV transmission lines, single conductor-tower leg gaps were studied. The gap lengths of gaps were $4 \mathrm{~m}, 5 \mathrm{~m}, 6 \mathrm{~m}, 7 \mathrm{~m}$, and $8 \mathrm{~m}$, and the tower widths were $1 \mathrm{~m}, 2 \mathrm{~m}, 3 \mathrm{~m}, 4 \mathrm{~m}, 5 \mathrm{~m}$, and $6 \mathrm{~m}$. The breakdown voltage of the above gaps was calculated by the breakdown voltage calculation method and the results are shown in Figure 5.

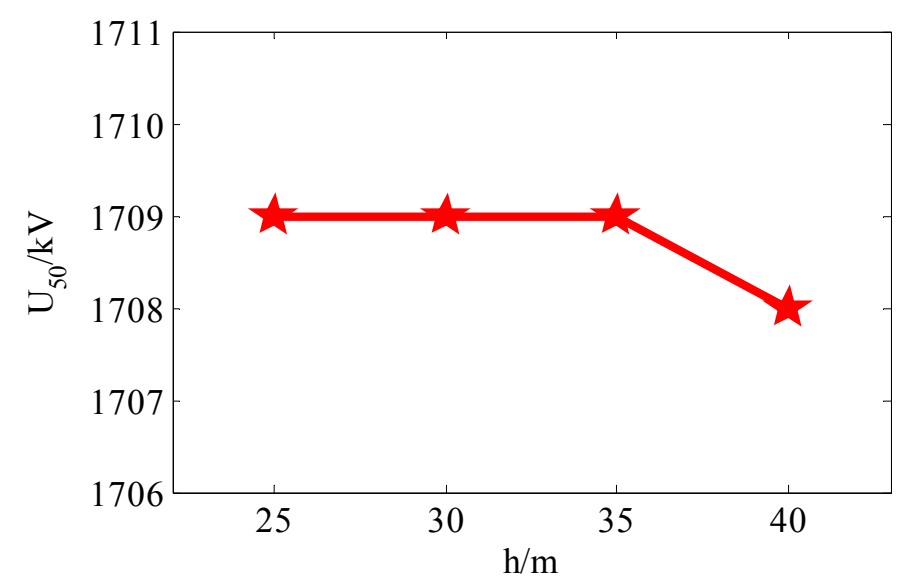

Figure 4. $U_{50}$ of conductor-tower gaps with different heights.

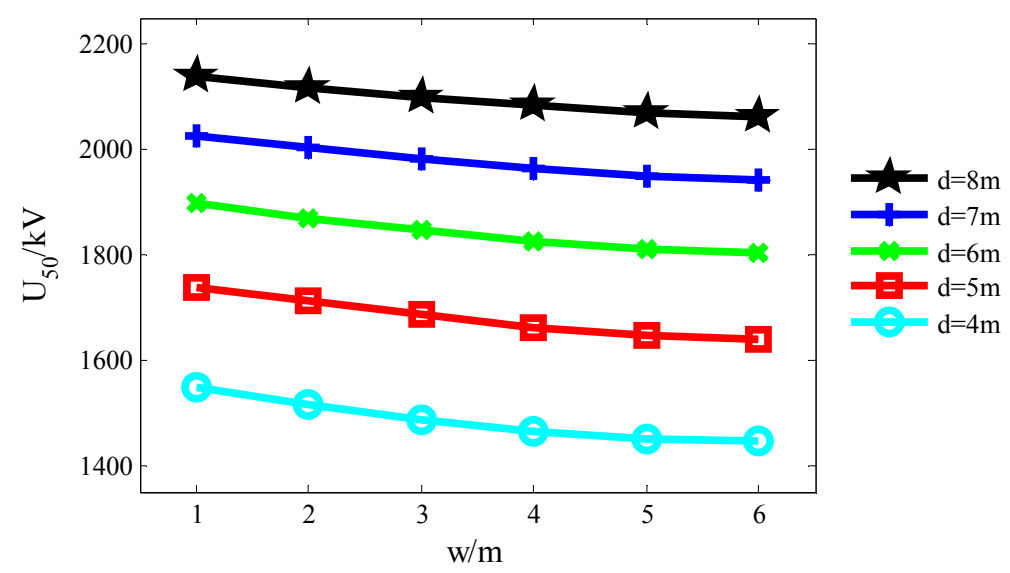

Figure 5. $U_{50}$ of conductor-tower gaps with different widths.

The results show that when the gap length was $8 \mathrm{~m}$, the breakdown voltage with a tower width of $6 \mathrm{~m}$ was $3.6 \%$ lower than that with a tower width of $1 \mathrm{~m}$. When the gap length was $4 \mathrm{~m}$, the breakdown voltage with a tower width of $6 \mathrm{~m}$ was $6.4 \%$ lower than that with a tower width of $1 \mathrm{~m}$. These results are consistent with the conclusions of [15]. Fitting the results, the tower-width discharge model of transmission lines with a tower width in the range of $2-6 \mathrm{~m}$ is obtained:

$$
U_{50(w)}=U_{50(1)}\left(1-0.014 w+\frac{w d}{1000}\right)
$$

The model is verified by the test results of [26]. The breakdown voltage of the gap with a tower width of $5 \mathrm{~m}$ was calculated by the tower-width discharge model and a previous formula based on the breakdown voltage of the gap with a tower width of $2 \mathrm{~m}$. As shown in Figure 6, the calculated results of the tower width discharge model were closer to the experimental data than those of previous formulas, with a maximum error of $3 \%$, which proves the correctness of the tower-width discharge model. 


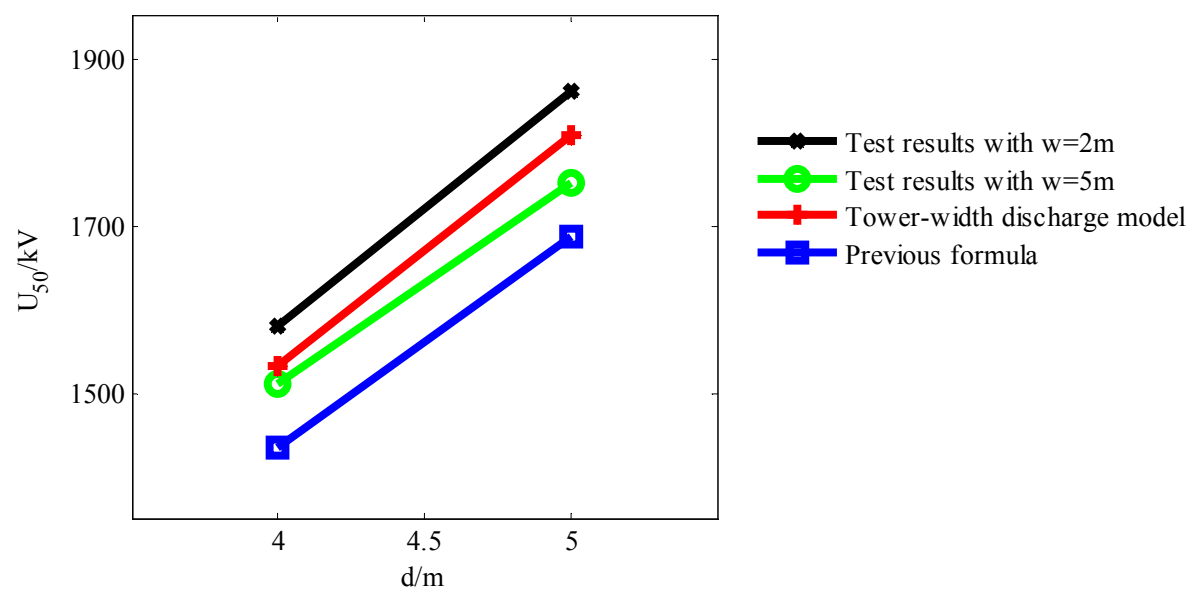

Figure 6. Comparison results between the tower-width discharge model, previous formulas, and tests.

\section{Discharge Model}

The breakdown voltage calculation method can effectively calculate the breakdown voltage of UHV transmission lines with different tower types. However, this method still needs to build a solid model, a finite element simulation calculation, and other processes, which has certain complexity, and the discharge characteristics are not intuitive enough. The discharge model of UHV transmission lines is obtained by studying different gap characteristics factor of gaps.

According to the general model of the continuous leader inception voltage, Equation (11), it can be concluded that the difference in continuous leader inception voltage in the same high voltage electrode gap is caused by the difference in gap characteristic factors. Therefore, according to the continuous leader inception voltage model of conductor-plane gaps, Equation (13), it can be considered that in gaps of the conductor electrode, the model of the continuous leader inception voltage is:

$$
U_{l c}=\frac{U_{c \infty}}{1+\frac{A}{R_{c t}}}=\frac{U_{c \infty}}{1+\frac{R_{c p}}{R_{c t}} \cdot \frac{A}{R_{c p}}}=\frac{2247}{1+J \cdot \frac{5.15-5.49 \ln a}{d \ln \frac{2 d}{a}}}
$$

where $J$ is the difference factor between the conductor-plane gap characteristic factor $R_{c p}$ with a gap length $d$ and the conductor-tower gap characteristic factor $R_{c t}$ with a tower width of $1 \mathrm{~m}$ and a gap length $d$. Its expression is as follows:

$$
J=\frac{R_{c p}}{R_{c t}}
$$

As shown in Figure 7, in order to determine the difference factor of different tower types, the gap characteristic factors of conductor-cathead-tower window gaps, conductor-cathead-tower side gaps, double-circuit-tower gaps, and conductor-plane gaps were calculated. The gap lengths of the above gaps were $5 \mathrm{~m}, 6 \mathrm{~m}, 7 \mathrm{~m}$, and $8 \mathrm{~m}$. The tower widths of the cathead-tower window, the cathead-tower side, and the double circuit-tower were $1 \mathrm{~m}$. The radius of the conductor was $0.05 \mathrm{~m}$, and the length was $20 \mathrm{~m}$. The tower model was made according to the actual tower 1:1 size.

Gap characteristic factors of different gaps after calculation are shown in Figure 8. According to Equation (19), the difference factors of the conductor-cathead-tower window gaps with different lengths were within the range of $1.21 \pm 3 \%$. The difference factors of the conductor-cathead-tower side gaps with different lengths were within the range of $1.01 \pm 4 \%$. The difference factors of the conductor-double-circuit-tower gaps with different lengths were within the range of $1.17 \pm 5 \%$. As a result, the difference factor $J$ of different tower types was 1.21 for the cathead-tower window gaps, 1.01 for the cathead-tower side gaps, and 1.17 for the double-circuit-tower gaps. 


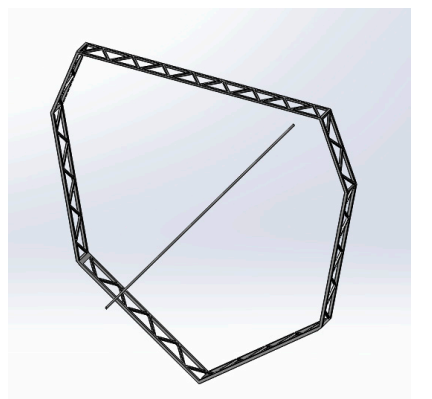

(a) Conductor-cathead-tower window gaps

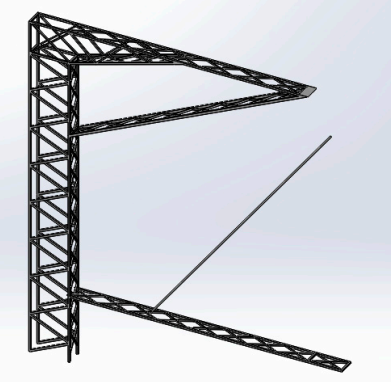

(c) Conductor-double-circuit-tower gaps

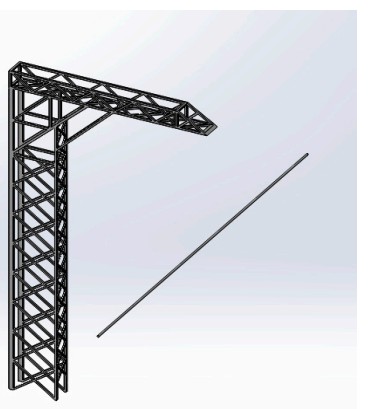

(b) Conductor-cathead-tower side gaps

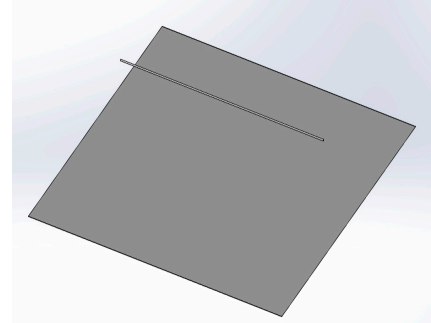

(d) Conductor-plane gaps

Figure 7. Different conductor gaps.

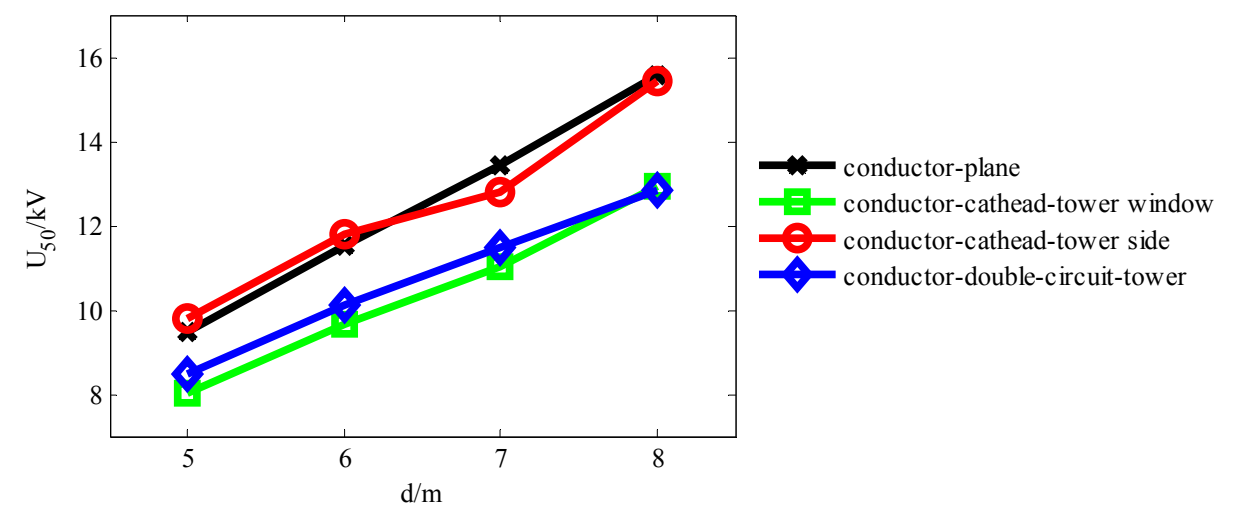

Figure 8. Gap characteristic factors of different gaps.

Therefore, according to the principle of capacitance equivalence, the continuous leader inception voltage model of UHV transmission lines is:

$$
\begin{gathered}
U_{l c}=\frac{2247}{1+J \cdot \frac{5.15-5.49 \ln a_{e}}{d \ln \frac{2 d+r_{b}+a_{l}}{a_{e}}}} \\
{\left[\begin{array}{c}
J_{c h-t-w}=1.21 \\
J_{c h-t-s}=1.01 \\
J_{d-c-r}=1.17
\end{array}\right.}
\end{gathered}
$$

where $J_{c h-t-w}$ is the difference factor of the cathead-tower window gaps, $J_{c h-t-s}$ is the difference factor of the cathead-tower side gaps, and $J_{d-c-r}$ is the difference factor of the double-circuit-tower gaps.

Combined with the long air gap discharge model, the breakdown voltage of the gaps with a tower width of $1 \mathrm{~m}$ can be calculated. After that, the breakdown voltage of the gaps with an actual tower width can be calculated by the tower-width discharge model. 
The correctness of the models is verified by actual test results. In the process of designing the external insulation in transmission lines of $1000 \mathrm{kV} \mathrm{AC}$, the China Electric Power Research Institute (CEPRI) took the cathead-tower and double-circuit-tower as the objects with which to conduct experimental research on the discharge characteristics of the gaps [27-29]. The test was carried out at the CEPRI UHV outdoor test site. The tower used in the test was the same as the actual tower. The conductor parameters are shown in Table 1. Considering the switching overvoltage level of transmission lines, the switching impulse with a front time of $250 \mu$ s was used in the test.

Table 1. Conductor parameters.

\begin{tabular}{ccc}
\hline$n$ & $a_{l} / \mathrm{m}$ & $r_{b} / \mathrm{m}$ \\
\hline 8 & 0.0138 & 0.52 \\
\hline
\end{tabular}

According to the continuous leader inception voltage model of UHV transmission lines, the long air gap discharge model, and the tower-wide discharge model, the breakdown voltage of different types of conductor-tower gaps is displayed in Table 2. After comparing the calculated results with the experimental results of CEPRI, the errors were not more than $5 \%$, which proves the correctness of the models.

Table 2. Calculation of different gaps breakdown voltage.

\begin{tabular}{|c|c|c|c|c|c|}
\hline Types & $d / \mathrm{m}$ & $w / \mathrm{m}$ & $U_{50} / \mathbf{k V}$ & Experimental $U_{50} / \mathrm{kV}$ & Error \\
\hline \multirow{3}{*}{ cathead-tower window } & 6.7 & 2.6 & 1890 & 1801 & $4.95 \%$ \\
\hline & 7.7 & 2.6 & 2033 & 1942 & $4.70 \%$ \\
\hline & 5.6 & 1.4 & 1819 & 1789 & $1.69 \%$ \\
\hline \multirow{3}{*}{ cathead-tower side } & 6.5 & 1.4 & 1964 & 1970 & $0.32 \%$ \\
\hline & 7.5 & 1.4 & 2103 & 2115 & $0.56 \%$ \\
\hline & 5.5 & 1.2 & 1730 & 1673 & $3.39 \%$ \\
\hline \multirow{3}{*}{ double-circuit-tower } & 6 & 1.2 & 1816 & 1795 & $1.17 \%$ \\
\hline & 6.5 & 1.2 & 1896 & 1907 & $0.58 \%$ \\
\hline & 7 & 1.2 & 1970 & 2000 & $1.48 \%$ \\
\hline
\end{tabular}

\section{Conclusions}

In order to reduce real tower discharge test costs, the discharge characteristics of UHV transmission lines were studied, and the following conclusions were obtained:

(1) In UHV transmission lines, line height had little influence on the breakdown voltage of air gaps.

(2) A tower-width discharge model was presented by fitting the breakdown voltage of air gaps with different gap lengths and tower widths. The model shows the influence of tower width on the breakdown voltage of air gaps.

(3) A continuous leader inception voltage model of UHV transmission lines was presented, which calculates the breakdown voltage of UHV transmission line air gaps combined with the long air gap discharge model and the tower-width discharge.

Author Contributions: Conceptualization and supervision by L.W.; methodology by J.G.; validation by J.G. and B.S.; investigation by Q.Z. and J.G.; writing by J.G.

Funding: This research received no external funding.

Conflicts of Interest: The authors declare no conflict of interest.

\section{References}

1. Shu, Y.; Chen, W. Research and Application of UHV Power Transmission in China. High Volt. 2018, 3, 1-13. [CrossRef] 
2. Wan, W.; Huo, F.; Xie, L.; Liu, Y.; Xu, T. Summary of research on flashover characteristics of long air-gaps. High Volt. Eng. 2012, 38, 2499-2505. [CrossRef]

3. Alexandrov, G.N.; Ivanov, V.L. Electrical strength of air gaps and insulator strings under the $500 \mathrm{kV}$ system. Electr. Technol. USSR 1962, 3, 460-473.

4. Hileman, A.R.; Guyker, W.C.; Wmith, H.M. Line insulation design for APS 500 kV system. IEEE Trans. Power Appar. Syst. 1967, 8, 987-994. [CrossRef]

5. Guyker, W.C.; Hileman, A.R.; Wittibschlager, J.F. Full-scale tests for the allegheny power system $500 \mathrm{kV}$ tower-insulation system. IEEE Trans. Power Appar. Syst. 1966, 85, 614-623. [CrossRef]

6. Zhang, R. Review on switching impulse flashover characteristics and the clearance for $500 \mathrm{kV}$ towers. High Volt. Eng. 1978, 4, 51-62.

7. Sun, Z.; Li, B. Studies on flashover characteristics of air gap of $\pm 500 \mathrm{kV}$ DC guyed tower under composite voltage. Power Syst. Technol. 1993, 32-35. [CrossRef]

8. Sun, Z.; Li, B.; Ding, Y.; Li, Q. Air Gap Flashover Characteristics and Selection of Gap Distances for $\pm 800 \mathrm{kV}$ UHVDC Transmission Project. Power Syst. Technol. 2008, 32, 8-12. [CrossRef]

9. Rizk, F.A.M. A model for switching impulse leader inception and breakdown of long air-gaps. IEEE Trans. Power Deliv. 1989, 4, 596-606. [CrossRef]

10. Rizk, F.A.M. Switching surge strength of air insulation: Leader inception criterion. IEEE Trans. Power Deliv. 1989, 4, 2187-2195. [CrossRef]

11. Qiu, Z.; Ruan, J.; Huang, D.; Shu, S. Breakdown voltage prediction method of rod-plane air gaps based on support vector machine and its applications. Trans. China Electrotech. Soc. 2017, 32, 220-228. [CrossRef]

12. Qiu, Z.; Ruan, J.; Jin, Q.; Wang, X.; Huang, D.; Shu, S. Switching impulse discharge voltage prediction of EHV and UHV transmission lines-tower air gaps by a support vector classifier. IET Gener. Transm. Distrib. 2018, 12, 3711-3717. [CrossRef]

13. Qiu, Z.; Ruan, J.; Huang, D.; Pu, Z.; Shu, S. A prediction method for breakdown voltage of typical air gaps based on electric field features and support vector machine. IEEE Trans. Dielectr. Electr. Insul. 2015, 22, 2125-2135. [CrossRef]

14. Qiu, Z.; Ruan, J.; Xu, W.; Huang, C. Energy storage features and a predictive model for switching impulse flashover voltages of long air gaps. IEEE Trans. Dielectr. Electr. Insul. 2017, 24, 2703-2711. [CrossRef]

15. Gao, J.; Wang, L.; Zhang, Q.; Song, B.; Liu, K.; Xiao, B. Switching Impulse Discharge Characteristics of UHV Transmission Line Air Gaps. IEEJ Trans. Electr. Electron. Eng. 2019, 14. accepted.

16. He, H.; He, J.; Chen, W.; Xie, S.; Xiang, N.; Chen, J.; Gu, S. Comparison of positive leader propagation in rod-plane and inverted rod-plane gaps. IEEE Trans. Plasma Sci. 2012, 40, 22-28. [CrossRef]

17. Zhou, X.; Chen, S.; Wang, H.; Zeng, R.; Zhuang, C.; Yu, J.; Ding, Y. Experiment on leader propagation characteristics of air gaps in UHVDC transmission towers under positive switching impulse voltages. CSEE J. Power Energy Syst. 2015, 1, 42-48. [CrossRef]

18. Diaz, O.; Hettiarachchi, P.; Rahman, M.; Cooray, V.; Vayanganie, S.P.V. Experiment on leader propagation characteristics of air gaps in UHVDC transmission towers under positive switching impulse voltages. IEEE Trans. Dielectr. Electr. Insul. 2016, 23, 806-812. [CrossRef]

19. Liu, L.; Becerra, M. On the critical charge required for positive leader inception in long air gaps. J. Phys. D Appl. Phys. 2018, 51. [CrossRef]

20. LR Group. E Positive discharges in long air gaps. Electra 1977, 53, 31-153.

21. Gallimberti, I. The mechanism of the long spark formation. Le Journal de Physique Colloques 1974, 40, $193-250$. [CrossRef]

22. Petrov, N.I.; Allesandro, F.D. Assessment of protection system positioning and models using observations of lightning strikes to structures. Proc. R. Soc. Lond. Ser. A Math. Phys. Eng. Sci. 2002, 458, 723-742. [CrossRef]

23. Petrov, N.I.; Allesandro, F.D. Theoretical analysis of the processes involved in lightning attachment to earthed structures. J. Phys. D Appl. Phys. 2002, 35, 1788-1795. [CrossRef]

24. Rizk, F.A.M. Critical switching impulse breakdown of long bundle-conductor gaps. IEEE Trans. Power Deliv. 1996, 11, 373-383. [CrossRef]

25. Alexandorv, T.H. EHV Transmission Line Design, Ni Zongde Translated; China Water Power Press: Beijing, China, 1987. 
26. Chen, Y.; Wan, Q.; Meng, G.; Xie, L.; Xie, X.; Huo, F.; Hu, W. Influences of tower gap and tower leg width on switching impulse discharge voltage of $750 \mathrm{kV}$ transmission line. Transm. Distrib. Technol. 2007, 23, 8-11. [CrossRef]

27. Gu, D.; Zhou, P.; Chen, Y.; Huo, F. Selection of air clearance of $1000 \mathrm{kV}$ transmission line tower. High Volt. Eng. 2007, 33, 15-19. [CrossRef]

28. Jiao, B.; Huo, F.; Chen, Y.; Wan, Q.; Xu, T.; Gu, D.; Meng, G. External insulation characteristic for UHVAC transmission line with double-circuit on the same tower. High Volt. Eng. 2009, 35, 1526-1532. [CrossRef]

29. Zhang, Q. Research on Complex Gap Discharge Model of Live Working on EHV and UHV High Voltage Transmission Lines. Ph.D. Thesis, Wuhan University, Wuhan, China, May 2018.

2018 by the authors. Licensee MDPI, Basel, Switzerland. This article is an open access article distributed under the terms and conditions of the Creative Commons Attribution (CC BY) license (http://creativecommons.org/licenses/by/4.0/). 